\title{
Who Are Domestic Travel Agency Users and Who Buys Full Package Trips? A Study of Korean Outbound Travelers
}

\author{
Young-Joo AHN ${ }^{1}$, Seul Ki LEE ${ }^{2}$, Yoon-Young AHN ${ }^{3}$
}

Received: July 27, 2019 Revised: September 16, 2019 Accepted: September 24, 2019

\begin{abstract}
The purpose of this study is to identify differences based on demographic characteristics and travel-related characteristics: first, whether travelers used a domestic travel agency and second whether travelers purchased a full-package travel program. A sample selection probit model was used to provide simultaneous evaluation of the different characteristics of outbound travelers. The present study investigates how tourists make decisions based on two travel-pattern choices. It then goes on to explore the characteristics of outbound travelers from South Korea. The data is drawn from a nationwide survey in South Korea, and a total of 859 surveys were used for analysis. Due to the interdependent nature of the choices, a sample selection probit model was used to estimate outbound tourists' use of domestic travel agency and purchase of full travel package. Significant determinants of domestic travel agency use are identified as age, gender, marital status, party size, children, length of travel, and travel distance, while those of full travel package purchase are age, marital status, and travel purpose. Estimated results provide manifestations of differing travel needs of outbound travelers. the results of this study demonstrate differences between travel-agency users and full-package travel-program consumers and provide determinants that affect the purchase of full-package travel.
\end{abstract}

Keywords : Outbound Travel, Domestic Travel Agency, Full-package Travel, Travel Intermediary, Sample-selection Probit Model

JEL Classification Code : Z30, Z32, Z38

\section{Introduction}

\subsection{Research Background}

The demand for outbound travel is increasing. Worldwide, outbound travel plays an increasingly important role in boosting economies and strengthening interaction among countries. In Korea, outbound travel demand has

1 First Author, Research Assistant Professor, Department of Hotel and Tourism Management, Sejong University, South Korea. Email: yjahn@sejong.ac.kr

2 Associate Professor, Department of Hotel and Tourism Management, Sejong University, South Korea. Email: seulkilee@sejong.ac.kr

3 Corresponding Author, Associate Professor, Department of Hotel and Tourism Management, Sejong University, South Korea. [Postal Address: 209 Neungdong-ro, Gwangjin-gu, Seoul, 05006, South Korea] Email: koala@sejong.ac.kr

(c) Copyright: Korean Distribution Science Association (KODISA)

This is an Open Access article distributed under the terms of the Creative Commons Attribution Non-Commercial License (http://Creativecommons.org/licenses/by-nc/4.0/) which permits unrestricted noncommercial use, distribution, and reproduction in any medium, provided the original work is properly cited. grown dramatically. From fewer than 7.5 million outbound travelers in 2003, the Korea Tourism Organization (KTO) (2017) estimated the total number of Korean outbound travelers for 2016 to have been a whopping 22 million, which itself was a $15.9 \%$ increase over the 2015 totals (see Figure 1).

As the Internet has compelled rapid changes in the tourism industry, myriad previous studies have explored the changing role of traditional travel agencies (AguiarQuintana, Moreno-Gil, \& Picazo-Peral, 2016; Andreu, Aldás, Bigné, \& Mattila, 2010; Buhalis \& Law, 2008; Cheyne, Downes, \& Legg, 2006; Del Chiappa, 2013; Del Chiappa, Alarcón-Del-Amo, \& Lorenzo-Romero, 2016; Rajaobelina, 2018; Tsai, Huang, \& Lin, 2005; Tsaur \& Chen, 2018). This surge in scholarship has left the traditional role of travel agencies as intermediaries between suppliers and customers very much subject to debate.

Among the ongoing arguments are two critical issues, namely dis-intermediation and re-intermediation in traditional travel agencies (Andreu, Aldás, Bigné, \& Mattila, 2010; Bennett \& Buhalis, 2003). Dis-intermediation 
describes a reduced role for these traditional intermediaries in the tourism supply chain resulting from Internet-enabled direct sales between customers and suppliers. Reintermediation-sometimes tellingly termed cyberintermediation - is associated with the rapid growth of travel intermediaries online, platforms such as Expedia, Priceline, Airbnb, and other online travel agencies (OTAs), firms that have harnessed the Internet to create new channels for the purchasing of travel products and services (Andreu, Aldás, Bigné, \& Mattila, 2010; Bennett \& Buhalis, 2003).

Many researchers have proposed that increasing numbers of consumers prefer independent travel that they arrange for themselves through websites offered by online travel agencies to the classic travel packages arranged by traditional travel agencies (Buhalis \& Licata, 2002). However, Aguiar-Quintana, Moreno-Gil, and Picazo-Peral (2016) have pointed out that many traditional travel agencies have leveraged niche marketing strategies to maintain clients while specializing in authentic travel experiences superior to those available from OTAs. Indeed, personal interaction and customized service are indicated as the most important attributes that customers prefer when opting to use traditional travel agencies (Andreu, Aldás, Bigné, \& Mattila, 2010; Dolnicar \& Laesser, 2007).

In South Korea, the market share going to global online travel agencies has increased for sales of air tickets, hotel rooms, and rental cars. Although the number of domestic travel agencies in South Korea is, in fact, increasing, just a few wholesale domestic travel agencies occupy the lion's share of the market for domestic travel. Still, traditional travel agencies have endured in Korea, in part by adopting suggestions from academia urging them to prioritize IT and utilize e-commerce (Andreu, Aldás, Bigné, \& Mattila, 2010). Given that South Korea ranks as one of the most technology-savvy countries in the world, Korea's domestic travel agencies habitually operate their own websites and online booking platforms, complete with secure transaction systems. Consumers can thus opt to employ a domestic travel agency from an electronic device, enjoying quickness, convenience, and the comfort of native language and currency transactions. Moreover, they can purchase fully packaged travel programs at once or select, a la carte, the specific travel products and services they want. Examining the drivers of demand for domestic travel agencies and their full-package travel programs stand not only to help domestic travel intermediaries survive but also to thrive by maximize their profits.

However, little research has been done on the drivers of demand for outbound travelers using domestic travel agencies. In this study, a sample selection probit model was used to provide simultaneous evaluation of the different characteristics of outbound travelers in South Korea. Gaining a firm grasp of the different characteristics (e.g., socio-economic and travel-related traits) of outbound travelers who use domestic travel agencies and purchase full-package travel programs will help marketers and practitioners understand their target market.
Therefore, the purpose of this study is simultaneously to identify differences based on demographic characteristics and travel-related characteristics by using two dependent binary variables: first, whether travelers used a domestic travel agency and second whether travelers purchased a fullpackage travel program. These two choices are related to each other in this sample selection probit model. The present study investigates how tourists make decisions based on two travel-pattern choices. It then goes on to explore the characteristics of outbound travelers from South Korea.

\section{Literature Review}

\subsection{Outbound Travel in South Korea}

The outbound travel market in South Korea developed in step with the relatively short history of the Korean travel industry itself. Unlike developed states with economic legacies stretching back centuries, South Korea completely rebuilt its economy after the end of the Korean War in 1953. Soon thereafter, in 1961, the first Tourism Promotion Law was enacted. One year later, the International Tourism Corporation (ITC) was established to promote South Korea's tourism industry. The ITC was renamed the Korea National Tourism Corporation (KNTC) in 1982. Today, this entity endures as the Korea Tourism Organization (KTO), a branch of the Republic of Korea's national government housed within the Ministry of Culture and Tourism, commissioned to promote the country's tourism industry. However, from early on the central government imposed age restrictions on Korean travelers and regulated foreign currency rates; moreover, it did not allow Koreans to travel abroad for pleasure from 1960s through the 1980s. After the 1988 Olympic Games in Seoul, however, the central government finally eased its travel restrictions, and in 1989 Koreans quickly began adding to the ranks of world outbound tourists.

Figure 1 documents this process, showing how the number of Korean tourists has soared rapidly since 1989. Significant economic development, loosened government regulations, and simplified domestic and international travel procedures have all played key roles in facilitating this remarkable rise (Korea Culture \& Tourism Institute, 2016). The growth of Korean tourism was further buoyed by events such as the 2002 World Cup in Korea and Japan and the implementation of a five-day workweek system in 2003. At the same time, low-cost carriers proliferated and technology developed rapidly. Tourism growth in Korea has remained largely robust, rebounding after dips during crises such as the Asian financial crisis in 1997, a MERS (Middle East Respiratory Syndrome) outbreak in Korea in 2015, and Chinese tourist boycotts over the THAAD (the American Terminal High Altitude Area Defense anti-ballistic missile system) from 2015 to 2017.

Heightened globalization is prevalent throughout modern 
Korean society, with Koreans studying abroad, working overseas, and welcoming foreigners at remarkably high levels. The considerable awareness of developments outside the Korean Peninsula that accompanies such globalization has led to more Koreans travelling overseas as tourists. Korean consumer confidence has also gradually increased, including a rise in discretionary spending on such activities as overseas travel for business and leisure. As Korea's per capita GDP rose to USD\$27,538 in 2016 (World Bank), Koreans' consumption on the amenities of improved living standards also increased.

Koreans' desire for experiential consumption and quality of life are accordingly increasing, implying that they are now more willing to spend their discretionary income on leisure and travel activities even during periods of budget constraint (Korea Culture \& Tourism Institute, 2016). In addition, the number of trips and the amount of spending by Korean tourists has gradually increased apace. The average spending by Korean outbound tourists per person is approximately US\$1,200 (Korea Culture \& Tourism Institute, 2016) - though, after 2015, the travel expenditure of Korean outbound tourists per person decreased, as shown in Figure 1. According to the KTO (2016), an increasing number of young travelers and a higher number of low-costcarrier options are driving this decreased travel expenditure per person, meaning that while spending is down per capita, actual tourism activity is not.

According to the Korea Culture and Tourism Institute (2006), South Koreans rarely travelled abroad for leisure until 1989, as up to that point Korean citizens needed official permission to leave the country for short business or private trips. That dynamic and legal framework has changed dramatically. For example, the Free Trade Agreement between Korea and the U.S., which entered into force in 2012, helps increase leisure- and business-related travel to the States. In the 1990s, reciprocal visa policies significantly increased the number of Korean travelers to world tourism destinations, while, in 2008, South Korea became a visa-waiver program participant, allowing Korean citizens to travel visa-free to 172 countries for stays of up to 90 days. South Korea is also one of the few markets with a reciprocal trusted-traveler agreement.

Finally, convenient travel products and services for tourists include the expansion of low-cost carriers for international destinations, a proliferation of online travel information, and the emergence of online travel agencies. These changes in the nature of the tourism industry have contributed to more affordable outbound travel. Along with direct flight sales, the sales of tour packages also now enjoy high popularity for price-conscious consumers who mostly travel for leisure.

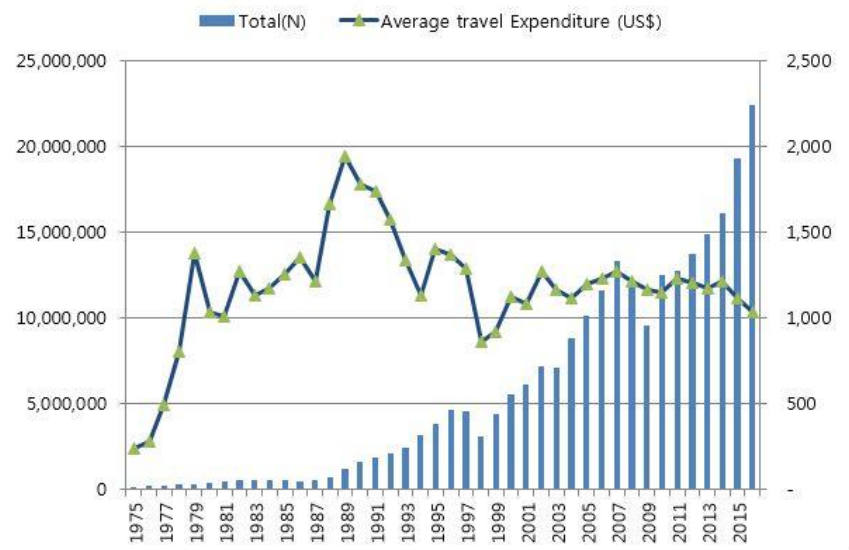

Figure 1: Korea's outbound travelers: A historical perspective

\subsection{Travel Agencies in South Korea}

Tourism regulation and law in South Korea defines a travel agency variously as a broker that sells travel-related services and products such as accommodations, car rentals, or attraction tickets, a related supplier, or a ground-travel operator. Travel agencies also provide a wide variety of services for convenient check-in procedures at travel destinations and provide travel-related information and travel packages customized for consumers.

Figure 2 shows statistics published by the Korea Association of Travel Agents (KATA) indicating that in the year 2000, Korean travel agencies delivered approximately 0.6 million Korean outbound travelers for a market share of nearly $12.3 \%$ of the Korean outbound market (KTO, 2016). The total number of Korean outbound travelers via Korean travel agencies had grown to approximately 7 million by 2015, with a market share approaching $24.5 \%$ in 2015 (KTO, 2016).

According to Korea Association of Travel Agents (KATA) (2016), the total number of travel agencies in Korea was reported at 6,745 in 2000 and had increased to 18,544 by 2015. The travel-agency industry thus appears to have progressed significantly; however, most of these new travel agencies were small businesses with total assets of less than 300 million Korean won (approximately $\$ 0.3$ million dollars) and fewer than ten staff members. With advanced information technology and the introduction of global online travel agencies, customers were able to compare prices and purchase travel goods on the Internet, whereas small travel agencies suffered from a lack of control over their cost structures and profit margins along with limited travelproduct development. In spite of the massive size of the overall Korean travel-agency industry, the top 30 travel agencies in South Korea dominate market share and generated US\$ 673 billion in revenue in 2015 (KTO, 2016). It is not an easy pond for the smaller fish.

South Korea's travel-agency industry used the Internet in a only very limited manner to help promote and provide travel products and package information in the 1990s, a time 
when few customers made purchases through the Internet. In the new millennium, as global OTAs (e.g., Expedia, Priceline, Ctrip, Airbnb, eDreams Odigeo, Lastminute) rapidly gobbled up market share in the travel-agency industry - with especially strong success among independent travelers-Korean travel agencies experimented with diverse business models, including both online and offline platforms, to reach customers. These efforts produced some success; even now, domestic and outbound trips continue to account for the largest share of travel-agency sales, with sales commissions, flight-ticket sales commissions, and hotel sales commissions following in line.

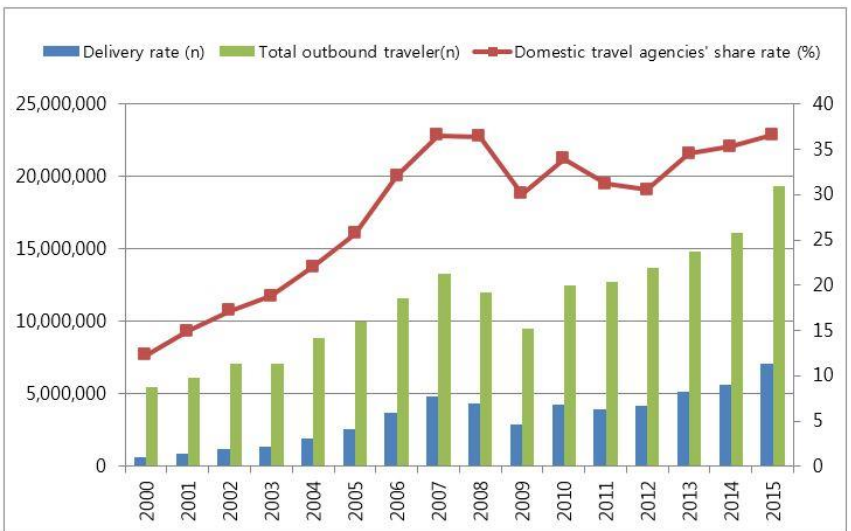

Figure 2: Domestic travel agencies' delivery (sending) rates in Korea

\subsection{Travel Agency Studies}

Previous travel-agency studies have studied industry aspects such as service quality and preferred attributes (Andreu, Aldás, Bigné, \& Mattila, 2010; Kim, Kim, \& Han, 2007; Lai, 2014; Tsang, Lai, \& Law, 2010), market segmentation of travel-agency users (Del Chiappa, 2013; Kuo, Chang, Cheng, \& Lai, 2013), strategies for building competitiveness (Aguiar-Quintana, Moreno-Gil, \& PicazoPeral, 2016; Zhang \& Morrison, 2007), and the packagetourism market (Chen \& Hsu, 2000; Castillo-Manzano \& López-Valpuesta, 2010; Dolnicar \& Laesser, 2007; FerrerRosell, Martínez-Garcia, \& Coenders, 2014; Money \& Crotts, 2003; Röikkönen \& Honkanen, 2013).

Previous research has shown that Asian tourists prefer to purchase all-inclusive package tours from travel agencies and have gone on to show that the important attributes of travel agencies influencing all-inclusive package tourists are agency reputation, recommendations of others, and friendly service by staff (Chen \& Hsu, 2012; Heung \& Chu, 2000; Huang, Chen, Song, \& Zhang, 2010). Travel agencies primarily work with tour operators and help conceive, develop, and sell package tours and services. Their most profitable activities are the sale of package travel programs and personalized travel consulting, mainly because airline companies have eliminated the commissions once paid to travel agencies. Moreover, package tourism has become undeniably popular in Asian countries. Therefore, research on package-tourism demand and tour operators has been dominated by the Asian perspective (Haung, Song, Haung, \& Lou, 2012; Huang et al., 2010; Tsai, Huang, \& Lin, 2005; Wang, Hsieh, \& Huan, 2000; Wang, Ma, Hsu, Jao, \& Lin, 2013; Wong \& Kwong, 2004; Wong \& Lee, 2012; Wong \& Wang, 2009, Yamamoto \& Gill, 1999, Zhang \& Morrison, 2007).

This present study, however, shifts the focus to the customer's side. It takes up the call that has been made by several studies, all of which urged that an analysis of travelagency users must consider different market segments and the key differences between travel-agency users (CastilloManzano \& López-Valpuesta, 2010; Cheyne, Downes, \& Legg, 2006; Del Chiappa, 2013; Kuo et al., 2013).

\subsection{Travel Agencies and the Demographic Characteristics of Customers}

Demographic characteristics are the most frequently used determinants in identifying the differences between travel-agency users and full-package travel-program consumers. The majority of previous studies have shown that demographic information such as age, gender, marital status, household income, and employment are key determinants of the differences delineating travel-agency users (Castillo-Manzano \& López-Valpuesta, 2010; Cheyne, Downes, \& Legg, 2006; Del Chiappa, 2013; Dolnicar, \& Laesser, 2007; Kim \& Prideaux, 2005; Morrison, Jing, O'Leary, \& Cai, 2001).

In terms of age, older age groups have been shown to utilize the Internet mainly to search for information while preferring to make purchases face-to-face at travel agencies (Castillo-Manzano \& López-Valpuesta, 2010; Del Chiappa, 2013; Grønflaten, 2009; Heung, \& Chu, 2000). Grønflaten (2009), in fact, found that older adults preferred travel agents to the Internet when they sought travel information and were then inclined to purchase an organized tour program.

Research has shown no significant difference in gender between travel-agency users and Internet users (Del Chiappa, 2013; Dolnicar \& Laesser, 2007; Law \& Wong, 2003). However, Castillo-Manzano and López-Valpuesta (2010) reported that females were more likely to use online booking than males, whereas men showed a higher preference for reservations made by phone.

Limited results exist regarding marital status as such. Married couples traveling with their children have been shown to be more likely to use travel agencies, largely for safety issues (Castillo-Manzano \& López-Valpuesta, 2010). It is clear that the propensity to purchase online increases with income (Cheyne, Downes, \& Legg, 2006; Law, Leung, \& Wong, 2004; Morrison, Jing, O'Leary, \& Cai, 2001). Cheyne, Downes, and Legg (2006) found that individuals with lower incomes made few online reservations. Employment may be relevant, as previous research has shown that the likelihood of engaging travel agencies 
increases with good professional positions (CastilloManzano \& López-Valpuesta, 2010; Dolnicar \& Laesser, 2007). However, Castillo-Manzano and López-Valpuesta (2010) determined that individuals having attained higher academic levels and students were more likely to make their travel bookings online. Overall, then, the findings in previous research have provided inconsistent outcomes when estimating the use of travel agency by demographic characteristics. The present study attempts to make a definitive and conclusive contribution in this unclear area, utilizing demographic information such as age, gender, marital status, household income, and full-time work as key determinants.

\subsection{Travel Agencies and Travel-related Characteristics}

Travel-related characteristics have been demonstrated to be important indicators for understanding the differences among travel-agency customers. The majority of previous studies have shown that travel-related characteristics such as travel-party size (number of travel companions), traveling with children, travel length (travel duration), travel distance, and travel purpose are key determinants explaining the differences in travel-agency users (Ferrer-Rosell, MartínezGarcia, \& Coenders, 2014; Del Chiappa, 2013; Money \& Crotts, 2003; Quiroga, 1990; Wong, \& Kwong, 2004).

Previous studies have indicated that party size (the number of travel companions journeying together) predicts the greatest difference in travel-agency use (Money \& Crotts, 2003; Quiroga, 1990; Wong, \& Kwong, 2004). People traveling with more travel companions prefer to use travel agencies than do people traveling alone, a finding that is especially relevant in the Asian market, where group travel dominates (Money \& Crotts, 2003). Of course, the phenomenon is not limited to previous studies have shown that people traveling with children are more concerned about security during their travel. Consequently, they tend to purchase air tickets and travel products and services through travel agencies (Castillo-Manzano \& López-Valpuesta, 2010; Money \& Crotts, 2003; Wong, \& Kwong, 2004).

Travelers with longer travel durations have been shown to be more likely to use a travel agency (Castillo-Manzano \& López-Valpuesta, 2010; Dolnicar \& Laesser, 2007; Ferrer-Rosell, Martínez-Garcia, \& Coenders, 2014; Money \& Crotts, 2003). Moreover, Money and Crotts (2003) reported that people traveling longer tended to reduce uncertainty by using travel agencies as reliable information sources.

Like duration, travel distance is also closely associated with the use of travel agencies (Castillo-Manzano \& LópezValpuesta, 2010; Dolnicar \& Laesser, 2007; Quiroga, 1990). Dolnicar and Laesser (2007) reported that people tend to utilize travel agencies for long-haul trips rather than for short-haul ones, which they were more likely to plan on their own. Travelers with medium- and long-haul distances before them are inclined to trust in the professionals to whom travel agencies provide access.

Travel purpose has also been linked to the use of travel agencies and full travel-package programs (CastilloManzano \& López-Valpuesta, 2010; Del Chiappa, 2013; Yamamoto \& Gill, 1999). People planning more complex travel itineraries or needing to plan special travel options such as honeymoons and business trips are more likely to go through a travel agency (Del Chiappa, 2013). Moreover, Dolnicar and Laesser (2007) reported that the activity of travel and the degree of difficulty of execution (e.g., summer relaxation activities, cities activities) are higher for the agency group than for the non-agency group. However, traveling for family visits, or visits with relatives or friends, is less often associated with the use of travel agencies.

Demographic characteristics and travel-related characteristics indicate differences in the decision to employ domestic travel agencies and to purchase full-package travel programs. However, previous research has presented inconsistent results in regard to demographic characteristics and travel-related characteristics. This study can hence provide a detailed profile of domestic travel-agency users and full-package travelers, with demographic characteristics and travel-related characteristics influencing the choices they make.

\subsection{Model}

Outbound travelers can select whether to use a domestic travel agency when they purchase specific travel-related products and services such as air tickets, hotel rooms, rental cars, or full travel packages. The choice to use a domestic travel agency or purchasing full-package travel programs can depend on personal travel propensity. When examining either individuals using a domestic travel agency or those purchasing all-inclusive travel packages, the value can be observed directly. However, the outcome effect may be confounded by the individual's self-selection. With an equation including a biased estimator, however, a sample selection probit model becomes an approach to correct for this selectivity bias. The two choices, using a domestic travel agency and purchasing a full-package travel option, are interdependent and estimated by using a bivariate sample selection model.

The appropriate model estimates the use of a domestic travel agency in its selection equation and the purchasing of a full-package travel program in its outcome equation. Two different parameters and selection probability are estimated flexibly in the sample selection model. This approach explicitly models individuals' prior choices; it then models their consumption on the prior selection. 


\section{Methods}

\subsection{Data Collection}

Individual-level data were obtained from the summer holiday travel survey in 2016, which is a nationwide survey in South Korea collected by Consumer Insight (http://www.consumerinsight.co.kr/). Consumer Insight is an online research company with 800,000 panels available to it. The online survey for this study was conducted by sending the survey link to individual email addresses and mobile text numbers for approximately 25,700 individuals, all randomly selected from the panels.

The participants were first asked whether they had traveled to international destination during the summer holiday. Those who replied 'yes' were then requested to proceed with answering the survey questions. The front page of the survey briefly explained the purpose of this study. Quota sampling was employed for data collection, in which the population was divided into subgroups based on factors like age, gender, and socioeconomic status. Subsequently, individuals from the various subgroups who met the quota criteria were asked to participate in the survey to ensure the composition of the final sample to be used. Proportional allocation was modified to estimate the percent accuracy represented and proportionally represented. A number of units (i.e., age, gender) were selected from each stratum. A total of 1,000 individuals who had experienced Korean outbound travel during the summer holiday therefore participated in this survey. However, unusable observations with missing values were deleted, leaving 859 available for analysis.

\subsection{Measures}

A series of questions was adopted to identify travelpurchase decisions during summer holidays. First, respondents were asked whether they had used a domestic travel agency during their summary holidays. Second, this group of individuals was asked whether they had bought a full-package travel program from a domestic travel agency. The use of a domestic travel agency during summary holidays and the purchase of a full-package travel program from a domestic travel agency were then binary coded $(1=$ yes, $0=$ no).

The individual characteristics affecting travel purchase decisions and the probability of using a domestic travel agency are variables that indicate age, gender, marital status, income, full-time employment status, travel-party size (i.e., number of travel companions), traveling with or without child(ren), travel duration, travel distance, and travel purpose.

An overview of these variables is presented in Table 1. Age is classified into four groups: 1) 20-29, 2) 30-39, 3) 4049 and 4) 50 and over. The following variables are binary coded: gender $(1=$ male, $0=$ female $)$ marital status ( $1=$ married, $0=$ others $)$, full-time employment status $(1=$ full-time employee, $0=$ other), and traveling with children ( $1=$ yes, $0=$ no). Household income level is classified into three different monthly household income levels: 1) under $4,000,000,2)$ 4,000,000-6,999,999, and 3) over 7,000,000 Korean won. Number of travel companions is classified into three different levels: 1) traveling alone, 2) traveling in a group of two people, and 3) traveling as three or more people.

Travel duration is classified into four different levels: 1) 3 days and 2 nights or less, 2) 4 days and 3 nights, 3) 5 days and 4 nights, and 4) 6 days and 5 nights or more. Travel distance is divided into groups based on the flight time in hours from South Korea: 1) within 4 hours (e.g., Mainland China, Japan, Taiwan), 2) within 4 to 7 hours (e.g., Southeast Asian countries such as Thailand, Cambodia, Vietnam), 3) within 7 to 15 hours (e.g., European countries, countries in North and South America). Finally, a total of 11 travel purposes are measured by a binary dummy variable that indicates the main purpose of travel during summer holidays: 1) Amusement park/Theme park/Hot spring visits, 2) City tour, 3) Art/Cultural tour, 4) Shopping, 5) Culinary/Food tour, 6) Historical/Heritage tour, 7) Naturalresource tour, 8) Festival/Event participation, 9) Recreation/Sports activities, 10) visiting family/relatives/friends, and 11) Rest/Relaxation. These variables allow us to estimate the outcomes that are regressed onto the influential variables.

\section{Results}

\subsection{Summary of Descriptive Statistics of Independent Variables}

Among the respondents $(\mathrm{n}=859 ; 61.0 \%), 524$ reported that they did not use a domestic travel agency during their summer holidays, while 335 (39.0\%) indicated that they used a domestic travel agency during their summer holidays. Among the respondents, 243 bought a full-package travel program from a domestic travel agency (28.3\%), 616 did not buy a full-package travel program from a domestic travel agency during their summer holidays (71.7\%).

Table 2 presents the summary statistics for the independent variables described above. Approximately 50.9\% of the respondents were male. The respondents were evenly distributed among the four age categories. Approximately $55.9 \%$ of the respondents were married. The highest number of respondents reported an income of 4,000,000-6,999,999 Korean won (KRW) (43.1\%) followed by more than $7,000,000$ Korean won (KRM) $(34.2 \%)$, and less than 4,000,000 Korean won (KRW) (22.7\%). Approximately $78 \%$ of the respondents were full-time employees. Approximately $24.7 \%$ of the respondents were traveling with children. Among the respondents, $47.1 \%$ of the respondents reported that they traveled with more than three people, and $41.1 \%$ reported that there were two people in their travel group. Most of the respondents chose travel destinations to which they could arrive within three hours by airplane (49.5\%), 
followed by a flight time within seven hours (29.6\%) and a flight time within fifteen hours $(21.0 \%)$. The purpose of travel was most often given as natural-resource tour (19.3\%), then city tour (16.6\%), then historical/heritage tour $(14.9 \%)$, the rest and relaxation $(14.4 \%)$, and finally culinary/food tour $(12.6 \%)$.

Table 1: Overview of variables and models

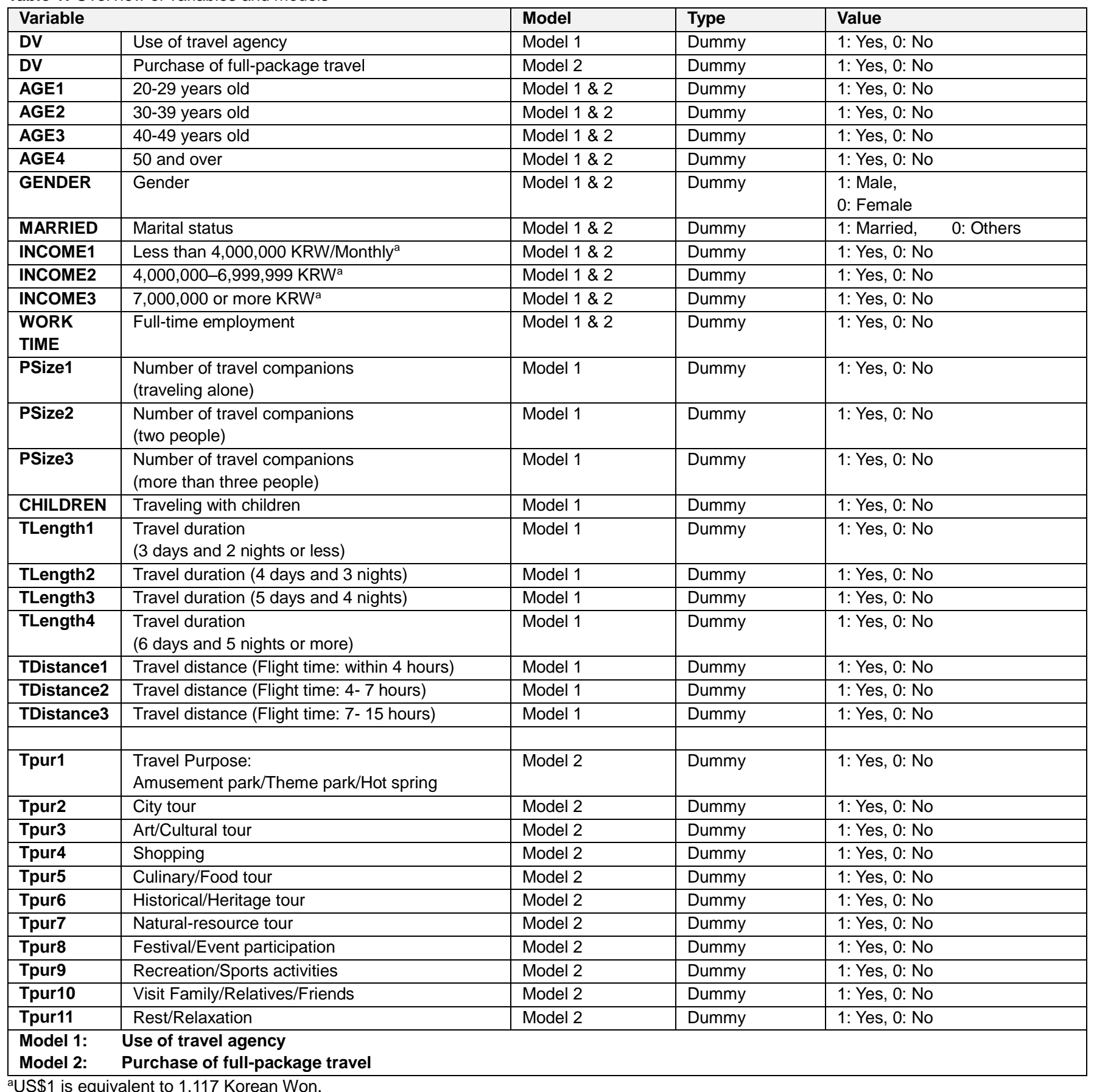


Table 2: Summary descriptive statistics of independent variables

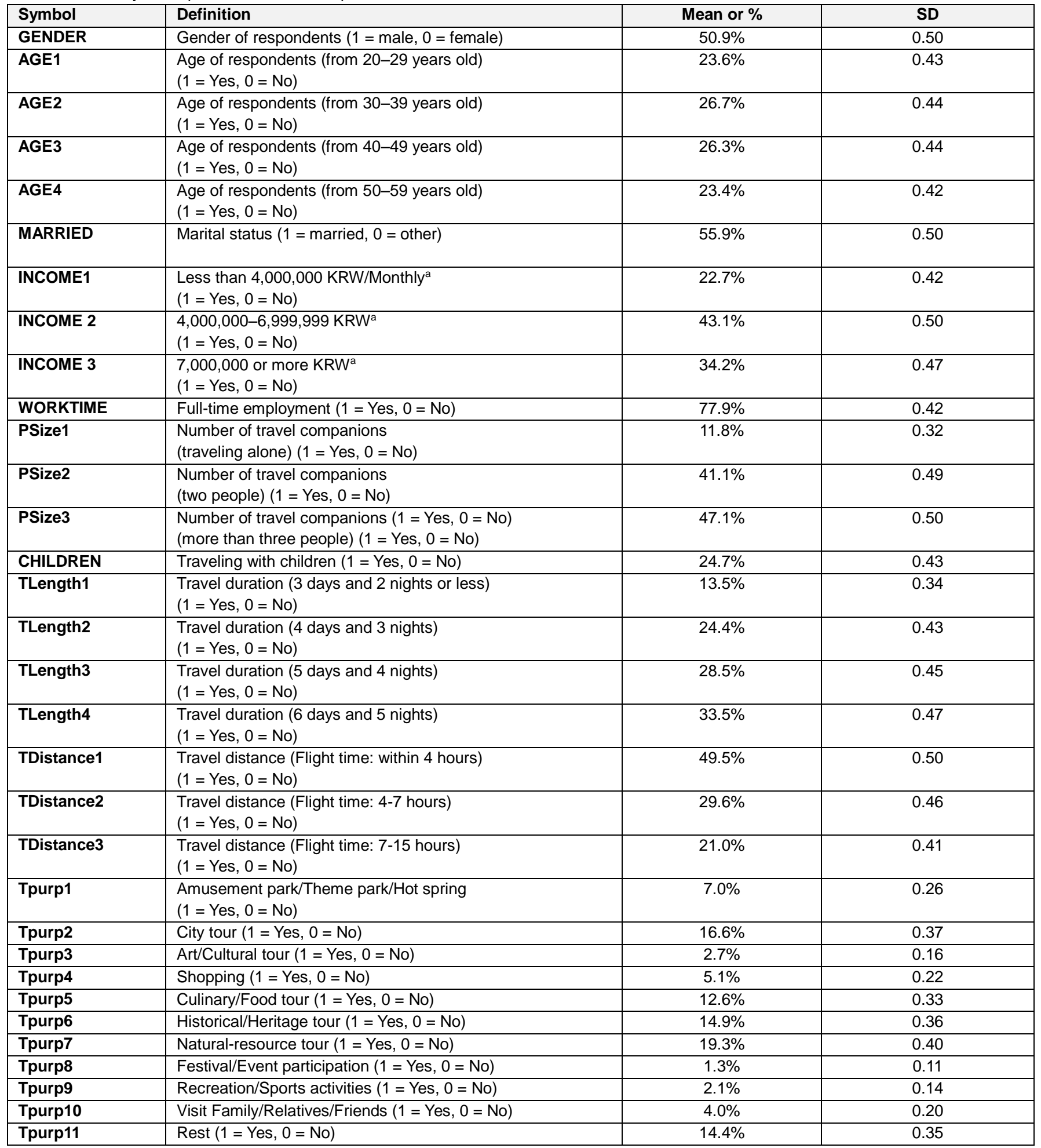

aUS $\$ 1$ is equivalent to 1,117 Korean won.

The sample selection probit model results show that a likelihood ratio test rejects the null hypothesis that $\rho=0$ at the $1 \%$ level. This finding provides evidence in favor of joint normality between the error terms from the initial decision to use a domestic travel agency during summer holidays and the subsequent purchase of a full-package travel program from a domestic travel agency, thereby suggesting that the sample selection probit model may be an 
appropriate specification for the summer-holiday travel decision modeled in this study.

Table 3 presents the results of the sample selection probit model. The probit coefficient represents the effect of the independent variables on the decision either to use or not use a domestic travel agency during summer holidays. Then, the effect among the individuals who chose to buy a fullpackage travel program from a domestic travel agency during the summer holidays was analyzed in the sample selection to estimate the regression coefficient of the decision whether to use a full-package travel program from a domestic travel agency.

\subsection{Model 1}

As shown in Table 3, individuals who were more likely to use a domestic travel agency during their summer holidays were those in the 40-years-old-and-over age group, those who were female, married persons, those traveling with more than three people, and those traveling with children. Individuals who traveled for more than six days and five nights were more likely to use a domestic travel agency during their summer holidays. Moreover, travelers who chose farther travel destinations, of a greater distance from South Korea, were also more likely to use a domestic travel agency. However, income and full-time employment did not show statistical differences.

\subsection{Model 2}

Those in the 50-and-over age group were more likely to buy a full-package travel program from a domestic travel agency during the summer holidays than were younger adults. Individuals who were married were less likely to buy a full-package travel program from a domestic travel agency than those who were not married. However, gender, income, and full-time employment did not show statistical differences. In terms of travel purpose, among 0people who bought a full-package travel program, those traveling for a historical/heritage tour, city tour, natural-resource tour, festival/event, recreation/sports activity, or art/cultural tour were more likely to travel through an agency.

Table 3: Results from sample selection probit model

\begin{tabular}{|c|c|c|c|c|c|}
\hline \multicolumn{3}{|l|}{ Model 1} & \multicolumn{3}{|c|}{ Model 2 (outcome) } \\
\hline \multicolumn{3}{|c|}{ Travel agency use } & \multicolumn{3}{|c|}{ Full-package travel } \\
\hline (Intercept) & -1.116 & $-4.882^{\star \star \star}$ & (Intercept) & 0.770 & $5.280^{\star \star \star}$ \\
\hline AGE3 & 0.315 & $1.904^{\circ}$ & AGE3 & 0.107 & 1.235 \\
\hline AGE4 & 0.505 & $3.031^{* *}$ & AGE4 & 0.226 & $2.513^{*}$ \\
\hline GENDER & -0.292 & $-3.086^{* *}$ & GENDER & -0.034 & -0.654 \\
\hline INCOME3 & -0.067 & -0.511 & INCOME3 & 0.067 & 1.010 \\
\hline WORKTIME & 0.170 & 1.407 & WORKTIME & -0.043 & -0.720 \\
\hline PSize2 & 0.207 & 1.251 & Tpurp2 & 0.274 & $3.028^{\star *}$ \\
\hline PSize3 & 0.758 & $4.363^{\star * \star}$ & Tpurp3 & 0.250 & $1.685^{\circ}$ \\
\hline CHILDREN & -0.427 & $-3.162^{\star *}$ & Tpurp4 & 0.187 & 1.295 \\
\hline \multirow[t]{3}{*}{ TDistance3 } & 0.762 & $4.659^{\star \star \star}$ & Tpurp9 & 0.328 & $1.727^{\circ}$ \\
\hline & & & Tpurp10 & -0.264 & -1.492 \\
\hline & & & Tpurp11 & 0.102 & 1.139 \\
\hline $\mathbf{N}$ & \multicolumn{2}{|c|}{859} & $\mathbf{N}$ & \multicolumn{2}{|c|}{524 censored/335 observed } \\
\hline \multicolumn{6}{|c|}{ Log Likelihood -604.936} \\
\hline \multicolumn{2}{|c|}{ Wald Chi-squared } & & \multicolumn{2}{|c|}{$175.862(\mathrm{p}<0.001)$} & \\
\hline
\end{tabular}

\section{Conclusion and Discussions}

\subsection{Conclusion and Implications}

The present study investigated the use of domestic travel agencies and the purchase of full-package travel programs using a probit model with sample selection. The proposed model examines the factors that influence the decision to use domestic travel agencies and to purchase full-package travel programs from a domestic travel agency.

The results of this study provide several theoretical implications. First, this study found that approximately $61 \%$ of outbound travelers did not use domestic travel agencies, whereas $39 \%$ of the respondents utilized domestic travel 
agencies. Among those traveling overseas during their summer holidays, only $28.3 \%$ of respondents purchased fullpackage travel programs from domestic travel agencies. These results suggest the rapid growth of global OTAs and Internet-enabled direct-sale channels for travel suppliers have caused sales through domestic travel agencies to decline in the outbound travel market in South Korea. Deintermediation and re-intermediation (Andreu, Aldás, Bigné, \& Mattila, 2010; Bennett \& Buhalis, 2003) appear to influence the changed demands of outbound travelers in South Korea, reducing the market share of domestic travel agencies.

Second, this study demonstrates a two-stage correction for reducing selectivity bias, which estimates the travel demand of outbound travelers. A probit model with sample selection was estimated; these steps explain the correlated choices, the use of domestic travel agencies, and the purchase of full-package travel programs from domestic travel agencies by demographic characteristics and travelrelated characteristics as indicated by the highly positive impact observed on outbound travelers using domestic travel agencies.

Third, the results of this study demonstrate differences between travel-agency users and full-package travelprogram consumers. Consistent with previous studies (Castillo-Manzano \& López-Valpuesta, 2010; Cheyne, Downes, \& Legg, 2006; Del Chiappa, 2013), the influential determinants of domestic travel-agency users are identified as age, gender, marital status, travel party size (number of travel companions), traveling with children, and travel duration and distance. The present results show that the profile of an outbound tourist who has a greater likelihood of using a domestic travel agency is someone 40 years old or older, female, married, traveling with more than three people in the group, traveling without children, for a shorter duration of travel, and traveling over considerable distance.

Fourth, the determinants that affect the purchase of fullpackage travel are age, marital status, and travel purpose, all of which is consistent with previous studies (CastilloManzano \& López-Valpuesta, 2010; Dolnicar \& Laesser, 2007). The results show that the profile of an outbound tourist who has a great likelihood of purchasing a fullpackage travel program is one who is 50 years old or older, unmarried, traveling on a historical/heritage, nature-based, city, art/cultural, festival/event, or recreation/sports tour. The finding on the purchasing of full travel packages presents further evidence for the strong influence of different travel purposes (Dolnicar \& Laesser, 2007).

The present study has several practical implications. First, this study posits the importance of outbound travelers for domestic travel agencies in South Korea. Unlike aspects of the previous literature, which have indicated that Asian outbound travelers heavily rely on full-package travel groups (e.g., Huang, Hsu, \& Chan, 2010; Wong \& Lee, 2012; Wong \& Wang, 2009), an increasing number of Korean outbound travelers are independent travelers. As the number of Korean outbound travelers rises, domestic travel agencies should create a responsive business model to access and leverage the outbound travel market in South Korea.

Second, the results indicate that domestic travel-agency users tend to be 40 years old and older, female, married, traveling with more than three people, traveling without children, traveling for shorter durations, and traveling farther. The demand for outbound travel among middle-aged and older adults is increasing. Previous studies have highlighted how affluent and highly educated older adults seek educational travel or memorable travel experiences with their significant others (Ahn \& Janke, 2011). Travel marketers and practitioners should develop diverse outbound travel programs to maximize comfort and convenience and minimize expected difficulties such as language barriers, night driving despite bad eyesight, driving long hours in unfamiliar foreign countries, and the difficulty involved in reaching planned travel destinations.

Domestic travel agencies in South Korea seem to be failing to reach the Korean young-adult market, such as those in the millennial generation. These millennial consumers tend to obtain travel information from online travel communities and may arrange their international travel without travel advice from domestic travel agencies. As the millennial market becomes the largest group of young consumers in South Korea, domestic travel agencies need to develop effective marketing for such young consumers. Marketers and practitioners also need to offer useful travel advice and provide travel-activity recommendations for those who need to travel to an international destination within a limited period.

Third, outbound travelers purchasing full-package travel must be regarded as a key profitable segment for domestic travel agencies. Especially, Korean middle-aged and older adults comprise an important target market. These travelers may face language barriers or have difficulty driving at night when overseas, so they tend to prefer full-package travel programs prepared by and purchased from domestic travel agencies. Travel agencies also need to provide the best possible value options in order to fit diverse travelers' different travel purposes. Domestic travel agencies may specialize in a particular field such as guided tours in historical cities, tours highlighting art and museums, tours of heritage sites, and visits to seasonal events and special festivals.

\subsection{Limitations and Further Research Suggestions}

There are several limitations to bear in mind when considering this study's findings. First, this research was limited to domestic travel agencies, regardless of their size or distinct features. Further research can go on to apply different approaches to capture unique travelers' profiles and travel characteristics based on various domestic travel agencies (e.g., market share, company size, features of travel intermediaries). Second, although this study contributes to the use of a sample selection model to evaluate the different 
characteristics of outbound travelers in South Korea simultaneously, this study only focuses on domestic travel agencies. Further research ought to replicate the model employed by this study, including global online travel agencies and domestic travel agencies to compare with the findings highlighted in this study. Third, this research only focuses on the consumer's side of the equation and is limited to the identification of demographic characteristics and travel-related characteristics for domestic travel-agency users engaging in outbound travel. Future studies should investigate diverse travel-product suppliers to provide effective strategies in promoting sales by domestic travel agencies in the outbound travel market.

\section{Reference}

Aguiar-Quintana, T., Moreno-Gil, S., \& Picazo-Peral, P. (2016). How could traditional travel agencies improve their competitiveness and survive? A qualitative study in Spain. Tourism Management Perspectives, 20, 98-108.

Ahn, Y., \& Janke, M. C. (2011). Motivations and benefits of the travel experiences of older adults. Educational Gerontology, 37(8), 653-673.

Andreu, L., Aldás, J., Bigné, J. E., \& Mattila, A. S. (2010). An analysis of e-business adoption and its impact on relational quality in travel agency-supplier relationships. Tourism Management, 31, 777-787.

Bennett, M., \& Buhalis, D (2003, January). Tourism and travel distribution: The travel agent's perspective. Insights, 25-30.

Bernardo, M., Marimon, F., \& Alonso-Almeida, M. (2012). Functional quality and hedonic quality: A study of the dimensions of e-service quality in online travel agencies. Information \& Management, 49, 342-347.

Buhalis, D., \& Law, R. (2008). Progress in information technology and tourism management: 20 years on and 10 years after the Internet-The state of eTourism research. Tourism Management, 29, 609-623.

Buhalis, D., \& Licata, M. C. (2002). The future eTourism intermediaries. Tourism Management, 23(3), 207-220.

Castillo-Manzano, J. I., \& López-Valpuesta, L. (2010). The decline of the traditional travel agent model. Transportation Research Part E, 46, 639-649.

Chen, J. S., \& Hsu, C. H. C. (2000). Measurement of Korean tourists' perceived images of overseas destinations. Journal of Travel Research, 38(4), 411-416.

Cheyne, J., Downes, M., \& Legg, S. (2006). Travel agent vs internet: What influences travel consumer choices? Journal of Vacation Marketing, 12(1), 41-57.

Del Chiappa, G. (2013). Internet versus travel agencies: The perception of different groups of Italian online buyers. Journal of Vacation Marketing, 19(1), 55-66.

Del Chiappa, G., Alarcón-Del-Amo, M., \& Lorenzo-Romero, C. (2016). Internet and user-generated content versus high street travel agencies: A latent gold segmentation in the context of Italy. Journal of Hospitality Marketing \&
Management, 25(2), 197-217.

Dolnicar, S., \& Laesser, C. (2007). Travel agency marketing strategy: Insights from Switzerland. Journal of Travel Research, 46 ,

133-146. https://doi.org/10.1177/0047287507299573

Ferrer-Rosell, B., Martínez-Garcia, E., \& Coenders, G. (2014). Package and no-frills air carriers as moderators of length of stay. Tourism Management, 42, 114-122.

Goldsmith, R., \& Litvin, S. W. (1999). Heavy users of travel agents: A segmentation analysis of vacation travelers. Journal of Travel Research, 38, 127-133.

Greene, W. H. (2012). Econometric analysis. 7th Edition, Prentice Hall, Upper Saddle River.

Grønflaten, Ø. (2009). Predicting travelers' choice of information sources and information channels. Journal of Travel Research, 48(2), 230-244.

Haung, Y., Song, H., Haung, G. Q., \& Lou, J. (2012). A comparative study of tourism supply chains with quantity competition. Journal of Travel Research, 51(6), 717-729.

Heckman, J. J. (1979). Sample selection bias as a specification error. Econometrica, 47, 153-161.

Heung, V. C. S., \& Chu, R. (2000). Important factors affecting Hong Kong consumers' choice of a travel agency for all-inclusive package tours. Journal of Travel Research, 39, 52-59.

Huang, G. Q., Chen, W. L., Song, H. Y., \& Zhang, X. Y. (2010). Game-theoretic study of the dynamics of tourism supply chains for package holidays under quantity competition. Tourism Economics, 16 (1), 197-216.

Kim. D. J., Kim, W. G., \& Han, J. S. (2007). A perceptual mapping of online travel agencies and preference attributes. Tourism Management, 28, 591-603.

Kim, S. S., \& Prideaux, B. (2005). Marketing implications arising from a comparative study of international pleasure tourist motivations and other travel-related characteristics of visitors to Korea. Tourism Management, 26, 347-357.

Korea Culture \& Tourism Institute. (2006). Developing policy directions for the domestic travel industry in the nationwide tourism era. Retrieved February 5, 2018, from

https://know.tour.go.kr/ptourknow/knowplus/kcti/detail.d o? seq $=246$.

Korea Culture \& Tourism Institute. (2016). Tourism policies and case studies of outbound tourism. Retrieved January 8, 2018, from http://www.kcti.re.kr/03_1.dmw?method=view\&reportId $=100 \&$ isSearch=true\&reportCategory=-

$1 \&$ reportTitle $=$ true $\&$ userName $=$ true $\&$ reportContent $=$ tru e\&reportYear=2016\&reportSeq $=1127 \&$ pageNum $=5 \& \mathrm{gr}$ oupNum=1.

Korea Tourism Organization (KTO). (2016). Annual reports. Korean tourism statistics. Retrieved April 30, 2018, from http://kto.visitkorea.or.kr/kor/notice/data/report/org/boar d/view.kto?id=427751.

Korea Tourism Organization (KTO) (2017). 2017 Annual 
reports. Korea, Monthly Statistics of Tourism. Retrieved January $\quad$ 2018, from https://kto.visitkorea.or.kr/eng/tourismStatics/keyFacts/K oreaMonthlyStatistics/eng/inout/inout.kto.

Kuo, N., Chang, K., Cheng, Y., \& Lai, C. (2013). How service quality affects customer loyalty in the travel agency: The effects of customer satisfaction, service recovery, and perceived value. Asia Pacific Journal of Tourism Research, 18(7), 803-822.

Lai, I. K. W. (2014). The role of service quality, perceived value, and relationship quality in enhancing customer loyalty in the travel agency sector. Journal of Travel \& Tourism Marketing, 31(3), 417-442.

Law, R., \& Wong, J. (2003). Successful factors for a travel website: Perception of Hong Kong online purchasers. Journal of Hospitality \& Tourism Research, 27(1), 118124.

Law, R., Leung, K., \& Wong, J. (2004). The impact of the Internet on travel agencies. International Journal of Contemporary Hospitality Management, 16(2), 100-107.

Money, R. B., \& Crotts, C. J. (2003). The effect of uncertainty avoidance on information search, planning, and purchases of international travel vacations. Tourism Management, 24, 191-202.

Morrison, A. M., Jing, S., O’Leary, J. T., \& Lipping, A. C. (2001). Predicting usage of the Internet for travel bookings: An exploratory study. Information Technology \& Tourism, 4(1), 15-30.

Morrison, A. M., Jing, S., O’Leary, J. T., \& Cai, L. (2001). Predicting usage of the Internet for travel bookings: An exploratory study. Information Technology \& Tourism, 4, 15-30.

Quiroga, I. (1990). Characteristics of package tours in Europe. Annals of Tourism Research, 17(2), 185-207.

Rajaobelina, L. (2018). The impact of customer experience on relationship quality with travel agencies in a multichannel environment. Journal of Travel Research, 57(2), 206-217.

Räikkönen, J., \& Honkanen, A. (2013). Does satisfaction with package tours lead to successful vacation experiences? Journal of Destination Marketing \& Management, 2, 108-117.

Tsai, H. T., Huang, L., \& Lin, C. G. (2005). Emerging ecommerce development model for Taiwanese travel agencies. Tourism Management, 26, 787-796.

Tsang, N. K. F., Lai, M. T. H., \& Law, R. (2010). Measuring E-service quality for online travel agencies. Journal of Travel and Tourism Marketing, 27(3), 306-323.

Tsaur, R., \& Chen, C. (2018). Strategies for cross-border travel supply chains: Gaming Chinese group tours to Taiwan. Tourism Management, 64, 154-169.

Wang, K., Hsieh, A., \& Huan, T. (2000). Critical service features in group package tour: An exploratory research. Tourism Management, 21, 177-189.

Wang, K., Ma, A., Hsu, M., Jao, P., \& Lin, C. (2013). Seniors' perceptions of service features on outbound group package tours. Journal of Business Research, 66, 1021-1027.

Wong, C. S., \& Kwong, W. Y. Y. (2004). Outbound tourists' selection criteria for choosing all-inclusive package tours. Tourism Management, 25, 581-592.

Wong, J-Y., \& Lee, W-H. (2012). Leadership through service: An exploratory study of the leadership styles of tour leaders. Tourism Management, 33(5), 1112-1121.

Wong, J., \& Wang, C. (2009). Emotional labor of the tour leaders: An exploratory study. Tourism Management, 30, 249-259.

Yamamoto, D., \& Gill, A. M. (1999). Emerging trends in Japanese package tourism. Journal of Travel Research, 38, 134-143.

Yoon, Y., \& Uysal, M. (2005). An examination of the effects of motivation and satisfaction on destination loyalty: A Structural Model. Tourism Management, 26(1), 45-56.

Zhang, H. Q., \& Morrison, A. (2007). How can the small to medium sized travel agents stay competitive in China's travel service sector? International Journal of Contemporary Hospitality Management, 19(4), 275-285. 